\title{
Responsible marketing for tourism destinations: Saint Catherine Protectorate, South Sinai, Egypt
}

\author{
Dalia F. Amara \\ Arab Academy for Science, Technology and Maritime Transport, Egypt \\ College of Management and Technology \\ Hotels and Tourism Department
}

\section{Keywords}

Responsible marketing, sustainable, ecotourism, environment, protectorate

\begin{abstract}
In the tourism industry, environmental management is a critical component for sustaining competitive advantage (Barrett, 1992), starting to recognize environmental improvement as an economic and competitive opportunity, rather than an annoying cost or inevitable threat. Unfortunately, there has been no consistent approach to environmental marketing practices in tourism. Some destinations neglect their environmental obligations, perhaps due to lack of guidelines and examples of best practice, or perhaps because they don't understand the benefits. Others exploit environmental communication for short-term gains, or fail to tell visitors about their environmental initiatives (Wight, 1994). A field survey was conducted based on qualitative approach, in order to investigate tourism and ecological experts 'opinions about specific environmental issues helping in applying responsible marketing for fragile areas. The purpose of the study is to highlight the complex relationship between tourism marketing and the environment protection responsibility and recommending environmentally responsible actions to Egyptian travel companies selling eco holidays, thus helping in the development of sustainable competitive strategies.
\end{abstract}

Corresponding author: Dalia F. Amara

Email address for corresponding author: daliaamara@hotmail.com

First submission received: 20th February 2017

Revised submission received: 14 th April 2017

Accepted: 12th May 2017

\section{1- Introduction}

The principle of sustainable tourism emphasizes the critical importance of environmental stewardship particularly for those destinations in fragile ecosystems areas (United Nations,1993). Similarly, the existing literature on competitiveness suggests that to be competitive, a destination must be sustainable from an environmental perspective (Ritchie and McIntosh, 2000). Yet, if environmental improvement is to provide a competitive opportunity there must be consideration of responsible marketing, defined as the balancing of environmental initiatives and environmental communication in order to achieve sustainable competitive advantage. Responsibility is a keyword in sustainable marketing. The principal ingredient of responsible marketing is not to incite consumers to consume less but to consume better. It is often perceived as the engine to the ethical modes of consumption in society (Sloan., et al. 2009).

Many tourism destinations may experience strong growth, but a challenge to this growth has appeared in the form of increased environmental awareness and opposition to such tourist activities by environmentalists. Some have raised concerns about the negative environmental impacts on natural and wildlife, about waste and visual pollution, noise pollution from tourist vehicles and activities, and compaction of solid causing increased surface run-off and erosion, change in risk of occurrence of landslips/slides in addition to damage to geological features (Hunter and Green, 1995). 
Williams (1998) explains tourism-environment relationship as one in which tourism benefits from being in a good quality environment and this same environment should benefit from measures aimed at protecting and maintaining its value as a tourist resource.

\section{2- Saint Catherine Protectorate}

Fifteen per cent of Egypt's total area has been turned into natural protectorates, and the country continues to add to the number of its natural protectorates, which is expected to reach 40 by 2017. In Sinai alone, there are seven protectorates - Ras Mohammad, St Catherine, Nabq, Abu Jallum, Ahrash, Zaraniq, and Taba"covering 14 per cent of Sinai's total area of 61,000 square kilometers. The city of Saint Catherine and other close towns, area of $4250 \mathrm{Km} 2$, fall within the region of Saint Catherine Protectorate, which was established in 1988. It is a unique high altitude eco-system with many endemic and rare species reserves or sanctuary. In 2002, UNESCO declared $640 \mathrm{~km}$ of the northern part of the St. Catherine Protectorate a World Heritage Site. The area combines religious and culturally significant places of global importance, lots of churches and monasteries including Mount Sinai, the 4th century Monastery of St. Catherine and numerous pre-historical sites, and relics from the Byzantine, Pharaonic and later eras. This arid mountain area supports a surprising diversity of flora and fauna. One of the principal goals of the Protectorate is to preserve the bio-diversity of the area's fragile eco-system, with an emphasis on the Nubian ibex and the wild medicinal and aromatic plants. Over 472 plant species, 19 are endemic to Sinai and 115 known for their medicinal value. There are many Sinai agamas, harmless foxes, rockhyraxes. In addition to, a wide range of migrating and resident birds from Europe, the area includes the world's smallest butterfly, known as the Sinai baton blue butterfly. Mammal species such as the endangered Nubian ibex, Dorcas gazelle, Arabian wolf and striped hyaena exist. Over 36 reptile species such as small geckos, large desert monitors and spiny-tailed lizards. In addition to, a large number of feral donkeys in the mountains who migrate to the region, and who put a big pressure on the eco-system and there is a move to reduce their numbers by the Saint Catherine City Council. St. Catherine Protectorate is home to 7000 bedouin from seven different tribes who play a vital role in supporting the protectorate as community guards, guides and hosts for ecotourism. The Bedouin have long-standing conservation ethics controlling the use and protection of trees and pastures.

The highest mountain in Egypt is Mount Catherine, and there are many other peaks in the area over 2,000 m (6,600 ft). The views from the highest mountains of St Catherine, Mount Sinai (Jebel Musa) are spectacular, and there are many other natural sights in the valley system. There are springs, creeks, water pools, and narrow canyons, steep valleys with huge boulders, amazing rock formations, and barren plains with islands of lush vegetation. On the top of the mountains, there are many interconnected basins with a unique high altitude ecosystem. There is a small orthodox chapel at the top. The Monastery constructed a small stone hut where trekkers and pilgrims can stay for overnight in the harshly cold weather.

There are many small ponds flowing under the rocks in lush Wadi Talaa Kibira, leading down to the biggest water pool of the area, Galt el Azraq, the Blue Pool. Its colour is actually changing according to the regular floods and melting snow; one brings sand from higher up, the next takes it further down and cleans the pool. It is safe for swimming. At the beginning of Wadi Shag there is a narrow canyon where there are permanent granite water pools, from which water is disappearing in the sandy floor at one place and only emerging before the end of the wadi. Water is trickling from the rock into a double fountain in WadiTubug. The lower fountain is for animals, locals drink from the upper one. It is considered safe, although you might need to treat the water.

\subsection{Ecotourism in St. Catherine Protectorate}

With ecotourism now controlling nearly 45 per cent of world tourism, Egypt is pouring money into green tourism with a view to promoting responsible and sustainable tourism, including 
eco-lodges, clean energy, recycling, and biodiversity. Interest in ecotourism has picked up pace after some of the most popular tourism destinations began to show the wear and tear of excessive use.

In order to stimulate awareness of the environment and to enhance political attention and public action, the Minister of Environmental Affairs Mustafa Hussein highlights his ministry's strategy to preserve Egypt's rich natural heritage while guarding the balance between touristic needs and ecological sense."Ecotourism at essence is a compromise between the tourist's need to have fun and nature's need to recover," When you are engaged in ecotourism, "you minimize the damage to nature while engaging in a lifestyle that brings you closer to all the wonders of nature offered," he added (Al-Ahram Weekly, 2012).

Protecting biological diversity is not only an environmental need, but rather "an economic imperative." Shedding the light on the Environment ministry's plan, it focuses on the intention to turn the spectacular Sinai 's protectorates into green destinations, "not only to promote environmental stability but also to protect the local culture.

The Ministry of Environment (MOE) has moreover set up local organizations to boost the income of Sinai inhabitants. One such organization, Dahab Katrin (Catherine's Gold), focuses on the preservation of medicinal herbs. It has planted 6,000 types of endangered plants, recorded oral history pertinent to medicine, and created many jobs in the process.

With one million tourists visiting Sinai's protectorates every year, an activity that brings $\$ 24$ million in income, Saint Catherine saw 446 tourists including foreign, Egyptian, and Arab visitors, according to CAPMAS, 2016.The MOE grasps the need for a comprehensive strategy on green tourism. One aspect of its strategy is to focus on sustainable development for the local community. This involves the creation of a legal and institutional framework, engaging the regional community in the activities of natural protectorates, turning protectorates into self-financing projects, and using revenue from protectorates to enhance infrastructure and train members of the local community.

Ecotourism in Sinai includes a wide range of activities, from diving to safari trips, bird watching, medicinal herb development, fishing, building reservoirs, and regulated use of mineral resources. Development efforts for Sinai, as stated in the five-year plan starting 2012, include 32 projects in ecotourism, handicrafts, agriculture, mining, and fishing. "These are expected to generate nearly 8,000 jobs. In St Catherine, efforts are underway to create Bedouin eco-lodges, a center for medicinal herbs research and marketing, a hotel, and a cable car for Al-Tur Mountain, as well as a service center for mountain climbing. In addition to an Environmental, training center and other visitors' information facilities planned for areas of Ras Sidr, Nekhl, Nabq, and Abu Jalloum. Meanwhile, the visitors' center in Ras Mohamed will undergo renovation; an eco-lodge and a training center for planting mangroves are under development. In Nuweiba and Al-Tur, agricultural training projects and projects for treating sewage water exist. According to MOE officials, the total cost of ecotourism development in Sinai is $\$ 43$ million. (See figure 1)

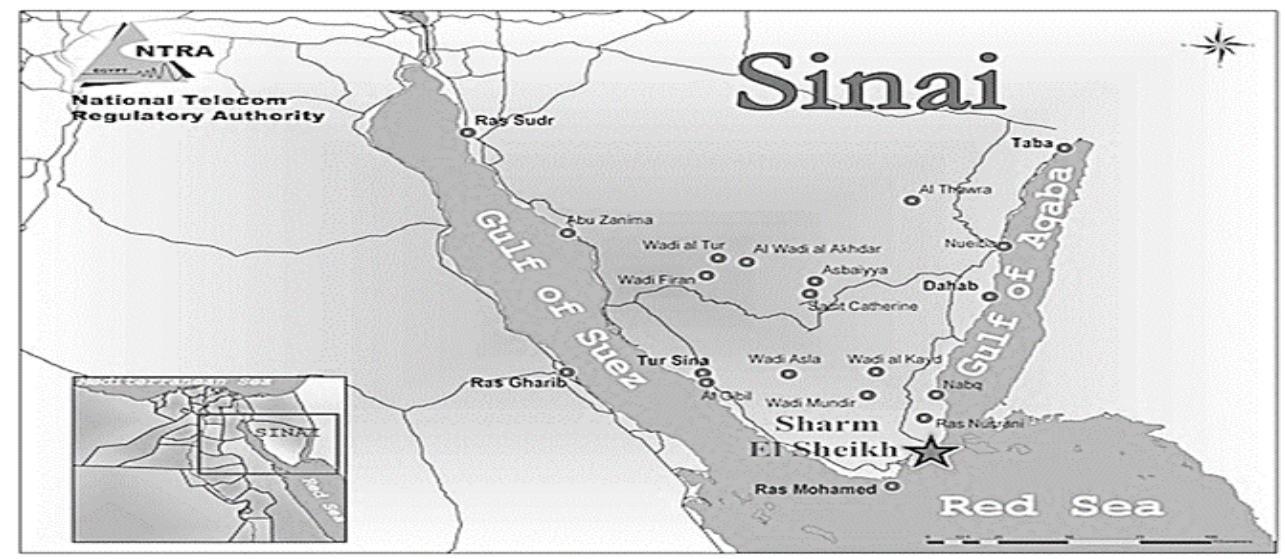

Figure1. Saint Catherine Protectorate and surrounding sites 


\section{Source:https://goo.gl/images/GxqNzR}

\section{3- Methodology}

Qualitative research was conducted through interviews with key stakeholders, observational research, and content analysis of communication materials, were used to identify how far Egyptian travel agents are applying a balance between responsible action and communicating their activities. In-depth interviews were conducted with individuals working in these organizations, environmental groups, the government, and other tourism associations. In the interviews the questions followed an interview guide format, with appropriate probes used to encourage an informal conversation. Probing was done by asking questions such as" why do you say that?", "can you tell me more about this point?" or "would you like to add anything else?" During interviews, some main concepts were explored based on the responsible marketing guidelines.

Participant observational research took place during the Saint Catherine hiking training course winter 2016. It was recognized the distinctive capabilities of observational methodologies for investigating services phenomena as advantages. In this study, the operations of Egyptian tour operators in practice were examined looking for evidence of environmental initiatives to support the material gathered in the interviews.

Content analysis was employed to examine the nature and level of communication of environmental activities by Egyptian tour operators. Content analysis uses an objective, systematic approach to measure the meaning of communicated material through the classification and evaluation of selected words, themes or concepts. Content Analysis goes beyond merely counting words to examining language intensely for the purpose of classifying large amounts of text into an efficient number of categories that represent similar meanings (Weber, 1990). The goal of content analysis is "to provide knowledge and understanding of the phenomenon under study. It has evolved since its introduction in the 1920s, largely in social science applications and has great promise as a tool for tourism marketing analysis (Fletcher, Witt and Moutinho, 1994). All types of communication materials were analyzed including tourist brochures, Web pages, newsletters, press releases and videos. Interviews with guides, ecologies' managers and overseas agents provided further insights into the level of environmental communication given to tourists both before and during a holiday.

\section{4- Data analysis}

Data analysis starts with reading all data repeatedly to achieve immersion and obtain a sense of the whole (Tesch, 1990) as one would read a novel. Then, data are read word by word to derive codes by first highlighting the exact words from the text that appear to capture key thoughts or concepts. Next, the researcher approaches the text by making notes of her first impressions, thoughts, and initial analysis. As this process continues, labels for codes emerge that are reflective of more than one key thought. These often come directly from the text and are then become the initial coding scheme. Codes then are sorted into categories based on how different codes are related and linked. These emergent categories are to organize and group codes into meaningful clusters (Patton, 2002).

Data obtained during interviews was recorded either written or through audio recording. The verbatim quotations were subsequently analyzed using conventional qualitative content analysis technique. Bryman (2001) also described qualitative content analysis as a strategy of researching for themes in one's data lies at the heart of coding approaches that are often employed in the analysis of qualitative data. The researcher worked on transcribing the answers and setting basic codes for them, and then a coding frame was set.

It was found useful to begin by coding text according to the specific research questions used to frame the interview. Codes are tags or labels for allocating units of meaning to the information compiled during the interviews. Codes were attached to phrases, sentences or whole paragraphs 
connected to a specific setting. The purpose of this step was to facilitate subsequent analysis by identifying all of the text associated with a particular elicitation or a specific question.

Coding resulted in the identification of large segments of text on broad topics; these segments formed the basis for an in-depth analysis within or across topics. In contrast to basic coding, the researcher attempted to use respondent's own terms.

\section{5- Results}

The results of the study suggest that, yet travel companies in Egypt are not proactive in environmental issues. They do not have specific environmental policy to be applied to such fragile ecosystem destinations. Some agents are close to publish samples of sustainability reports. Others started to implement heritage conservation and environmental initiatives programs, as an attempt to achieve all their responsible marketing and sustainability projects. The agent says that the environment, whether natural or man-made, has always been a cornerstone of its vision based on travel safety, quality of service and responsible behavior.

According to an agent marketing manager, understanding tourism sites' environmental issues is all about awareness as a travel agency is often a source of information about where things are going to go. He believes that tourism industry driven best practices are going to be important in the future, thus business best practices' observation is crucial.

Most of the travel companies become more interested to work with trained guides to keep a vigilant watch on natural tourists sightseeing. Conscious of the fact that it is the activities of tourists, which actively cause the harmful effects of tourism, some travel agents, have devised codes of conduct to guide tourists towards more sustainable behavior. Responsible marketing can be applied by involving 'ecotips and advice in brochures and other promotional materials. With the support of the Italian Cooperation, it was created what so called 'keep the holiday code', advising tourists to help in the environment protection and natural resources conservation at St. Catherine protectorate, while they are on holiday. The visitor code includes the following precautions; visitors are not allowed to disturb animals and plants, collect or damage rocks or geological features, drive off marked tracks or on vegetation, etc.

According to local external biologists, responsible behaviour 's goal is to prevent disturbance, and to ensure that tourism activities don't contribute to habitat mortality. As Butler (2002), said, "To work our operations so that the animals see us as a neutral influence in their lives". They claim that tourism seriously affects the area's habitat and that an avoidance distance is strongly supported by research and local wildlife biologists. According to Egyptian Environmental Affairs Agency reports, Dorcas gazelle population at El'qaa Plain has deteriorated over the last five years, as a result to the difficulty of controlling access due to the large size of the area. In addition, the area has been excluded from the buffer zone and the rangers have no jurisdiction to operate there (www.eeaa.gov.eg).

Results revealed that the biggest threat to the protectorate's unique ecological and aesthetic values is the presence of the largest garbage dump in Sinai that of Sharm el Sheikh City, which is located inside the protectorate (see figure 1). The condition of Wadi Mandar area and its surroundings have been deteriorated because of the unwise placement of this waste dump inside the protectorate. The dump is poorly managed and contains large quantities of uncovered plastic garbage; the wind blows it all and it disfigures the surrounding area.

Tourism operators assured that ecotourism trips to the area have been affected, because of the lack of environmental awareness of municipal decision makers. Lack of sufficient funds to increase number of garbage cleaners, and garbage cleaning tools and equipment (e.g., trucks and loaders), in general, all operations related to waste dump have ceased. They added that the poor condition of infrastructure and ecotourism opportunities could be substantially linked to the poor financing that the protectorate has faced since the end of the European funding in 2003. Despite the fact that they started to collect visitor entrance fees in 2005, which has generated over 6,000,000 LE 
per year (Fouda et.al, 2006), the St. Catherine protectorate's budget for the year 2006/2007 and until recent, has not exceeded 350,000LE.

The area undoubtedly, has a good potential for the development of ecotourism and ecologies. Much ecology was visited during the survey, AL Karm ecology is the first ecology built at the protected area, using environmental construction materials; such as natural stones, granite and basalt basement boulders and rocks from the valley floors. Palm tree stalks and palm tree fronds are used too. The ecology is owned, managed and operated by the local community. It operates on the principles of minimal environmental impacts: e.g., there is no electricity grid, it has solar heated showers. Battery lamps and torches are used for lighting. Braziers using wood for fuel are used for heating the rooms at night in winter. The lodge uses only candles, camp gas burners, and kerosene lamps. Only a standby generator is available for emergencies. There is no sanitary sewage network, but sanitary composting toilets, kitchen and dining facilities, are provided.

Due to water shortage in the St. Catherine, water conservation measures and water saving systems are used for water supply. A high altitude water well is the main water source, with free flow under gravity flow through pipes to a hidden slightly elevated water tank that is of a lesser altitude than the well, and higher than the lodge itself, and the water is again distributed using gravity to the kitchen area and wash areas (Hossam El-Borombaly etal.2014). Waste water (grey water) from the showers, wash basins and kitchen sinks is collected in gravity lines to an isolated tank with the capacity of one or two days' discharge. The tanks function is to treat, organic, biodegradable detergents, allowing suspended solids to settle at the bottom of the tank. All the used detergents should be strictly biodegradable. Grey water is filtered along multi-level stepped trenches covered in gravel, after storage, for physical and bacteriological treatment. Treated water is used to irrigate trees and shrubs in the orchard.

\section{6- Implications and Recommendations}

Saint Catherine Protectorate is a large and complex area, where a strong coordinating and controlling role is necessary with cooperation with the town council and stakeholders. The Ministry of Environment should put together a biological database and monitoring system while boosting ecotourism through legal measures, including a biological safety law.

Law enforcement has intensified and has become more effective in the area over time, but more patrols are needed and better training is needed for the new protectorate recruits.

An integrated public awareness strategy should be put into action to target tour guides, school children, local community and governmental organizations, and generally, all stakeholders. Bedouin eco-guide certification programs have begun to give accreditation to the environmentally committed local guides. Training of local guides and turning them into eco-guides is an essential step to seize business opportunities for the local inhabitants of the area and should be actively implemented.

St. Catherine visitor center has not yet reached its full operational capacity. This facility needs proper attention and planning to increase use. Implementation of the visitor management plan should be a priority during the next annual work plans, including the redesign of the visitor parking area and circulation system for the monastery. Under this plan an estimated 150,000 tourists would have had to pay to enter the area, which would have contributed significantly in reducing visitor impact (EEAA, 2017).

Protectorate has adapted a zoning plan and kept high ecological sensitivity areas in the impact free zones. It is recommended that the zoning maps be printed, posted in the headquarters offices, and training be carried out for the protectorate and town staff to better understand the zoning system and permitted uses.

Travel companies could work towards developing an eco-label scheme for tourism activities at protected areas. It seems highly probable that eco-labels will become increasingly important in tourism as in other industries (Buckley, 2001). A program of responsible tourism marketing 
benchmarking with best practice agents will be an important adjunct of an effective eco-labelling scheme. This will require travel companies to report regularly on their environmental management measures and performance.

New lodges should be built with the environment in mind. Eco development is an approach to design, construction and management that reduces the impact of buildings on the environment and offers many benefits to owners and occupants. These buildings use less energy and water, meaning they cost less to operate; often using natural ventilation and avoiding toxic adhesives and plastics; and they look better, blending into the environment and using sunlight to supplement heat and interior lighting. Any future lodges should follow best practices for environmentally sustainable design and construction, intended to guide future development.

Travel companies organizing tours in Saint Catherine should maintain waste reduction at every opportunity. For example, at lodging facilities, creating less waste or eliminating waste, this can be done by changing to reusable packaging where possible. Others donate edible, unused food to locals, allowing the feeding of food to animals. Yet, sewage treatment, and usage of environmentally products issues need to be studied, looking for more efforts to promote environmental stewardship.

In terms of communications, travel companies should promote their green mission and environmental initiatives produce brochures dedicated to the "holiday components and responsible behavior", describing the major environmental activities the agent is undertaking, or publish newsletters that talk about the "stewardship ethic" to ensure the long term viability of the area's natural and heritage resources. All tourism agents have their Web sites, a link from trips offers and packages to various protected areas such as the case of St. Catherine protectorate can lead to a separate Web page titled "Tourism and our planet" for example, where the reader is informed about energy-efficient light systems, recycling of cans, bottles and paper, water use reduction tips, etc. Promotional videos may be expensive, but they may also be a useful responsible marketing tool, helping visitors to learn more about the natural history of a destination and its conservation.

Other recommendations include travel companies may use cause responsible marketing to contribute to the well-being of society and to associate themselves with a positive cause that will reflect well on their corporate image. They can make the cause an important part of their business by integrating a non-commercial, socially redeeming value system into their tourism operation. This strategy may add an element of trust to the relationship between the agent, tourists and the area's stakeholders.

\section{7- Limitations and Further Research Proposals}

The study's survey was limited to local tourism managers and ecological experts' opinions excluding other stakeholders as well as tourists 'opinions. Focusing only on St. Catherine protectorate excluding other designated protectorates located in the same area. The issue of promoting responsible, sustainable tourism in remote, fragile ecosystem such as the case of St. Catherine protectorate is still wide open for exploration. Further research may include:

- Because of the importance of historical and cultural aspects of St Catherine attractions, the researcher aims to concentrate on a longitudinal work on the visitor management of the existing cultural/historic sites, and the surrounding area.

- Exploring the role played by St. Catherine's local community to revive local businesses.

- Discussing the future of St. Catherine area as a curative/ therapeutic tourism destination competing with other international curative destinations.

- Studying the profile of ecotour developers wishing to establish ecotourism operations in St. Catherine and other similar areas in Egypt.

- Lastly, sustainable development of tourism in deserts and mountains areas must be considered on its own terms, with due regard for the special character of these areas. 
In conclusion, the study provides important insights into the value of careful protection and responsible marketing of St. Catherine protectorate as a tourist destination attracting special interest visitors seeking new experiences in unspoiled environment and the importance of applying conservation approaches for natural and cultural destinations' resources and therefore may have significant implications for researchers and practitioners alike.

\section{8- References}

Al-Ahram Weekly7, June (2012), Promoting Ecotourism, Issue No. 1101 Travel, (http://weekly.ahram.org.eg/Archive/2012/1101/tr4.htm) [last access: March 2017].

Barrett, S. (1992). Strategy and the environment. Columbia Journal of World Business, 27(3\&4), 202208.

Bryman, A., (2001). Social Research Methods. University Press. Oxford.

Buckley, R. (2001). Tourism Ecolabels. Annals of Tourism Research, 29(1), 183-208.

Butler, D. (2002). CMH Land Resources Director. Personal Interviews, [5 February and 20 June 2002].

Central Agency for Public Mobilization and Statistics (CAPMAS). February 2016www.capmas.gov.eg.

Egyptian Environmental Affairs Agency , www.eeaa.gov.eg, [last access: January 2017]

Fletcher, J.E., Witt, S.F. \&Moutinho, L. (1994). Analytical Methods Applied to Tourism, Hemel Hempsted: Prentice-Hall.

Fouda, Moustafa, John Grainger, Waheed Salama, Sherif Baha El Din, Dan Paleczny, SamyZalat, Francis Gilbert (2006). Management Effectiveness Evaluation of Egypt's Protected Area System.Nature Conservation Sector, Egyptian Environmental Affairs Agency, Cairo.

Hunter, C. \& Green, H. (1995). Tourism and the Environment. A sustainable relationship? Routledge. London, pp. 93-121.

Hossam El-Borombaly, Mohamed Adel Yehia, and Sherine Khalil. (2014). the study of "Al Karm" Ecolodge in Saint-Katherine Protected Area South Sinai, Ain Shams University.

Nature Conservation Sector, Egyptian Environmental Affairs Agency, www.eeaa.gov.eg [July 14, 2007].

Patton, M. (2002). Qualitative Research and Evaluation Methods. $3^{\text {rd }}$ ed. Sage. Thousand Oaks, CA.

Philip Sloan, Willy Legrand, Joseph S., (2009). Sustainability in the Hospitality Industry. UK: El Sevier.

Ritchie,B. \& McIntosh R., (2000). Tourism: Principles, Practices, Philosophies. $8^{\text {th }}$ ed. John Wiley \&Sons.

Tesch, R. (1990). Qualitative research: Analysis types and software tools. Falmer Press. New York.

United Nations (1993). Agenda 21: Programme of Action for Sustainable Development. New York: United Nations Department of Public Information.

Weber. (1990). Basic Content Analysis. 2nd ed. Sage Publications. UK.

Wight, P. (1994). Environmentally responsible marketing of tourism. In E. Cater and G. Lowman (Eds.) Ecotourism: A Sustainable Option? ,39-55. New York: John Wiley \& Son.

Williams, S. (1998). Tourism Geography. Routledge contemporary Human Geography. London. 